\title{
Ciudad, espacio público y hábitat intergeneracional
}

\section{City, public space and intergenerational habitat}

Sergio García-Doménech*

Universidad de Alicante.

sergio.garcia@ua.es

* Doctor arquitecto por la Universidad Politécnica de Valencia, España. Profesor de urbanística y ordenación del territorio en la Universidad de Alicante, España. Especializado en planeamiento urbano, gestión y movilidad sostenible. Mantiene líneas de investigación sobre espacio público, planeamiento y gestión urbana, habiendo publicado varios artículos científicos y libros arbitrados sobre estas materias. 


\section{Resumen}

El envejecimiento de las sociedades avanzadas es un hecho. Los programas intergeneracionales suponen un avance para mejorar las brechas etarias y la cohesión social. La arquitectura y el urbanismo, fieles a su compromiso social, pueden aportar valiosas propuestas disciplinares. Entre estas propuestas, el espacio público mantiene su vigencia como clásica herramienta urbana de integración entre diferentes colectivos. Por otra parte, la nueva arquitectura residencial intergeneracional promueve la fusión programática y la interacción social. Como caso consolidado, se estudia la experiencia de la plaza de América en Alicante, España, ejemplo de combinación entre arquitectura social y espacio público con sentido urbano. Como conclusión, las propuestas habitacionales homogéneas y los modelos urbanos segregados pueden originar aislamiento social. Las políticas sociales deben apostar por iniciativas combinadas entre arquitectura y espacio público que, como la expuesta, cohesionan la sociedad y en definitiva, crean ciudad.

Palabras clave: Espacio público; Programa social; Hábitat intergeneracional; Paisaje urbano; Interacción social.

\section{Abstract}

The aging of advanced societies is a fact. Intergenerational programs are a step forward to improve age gaps and social cohesion. Architecture and urbanism, faithful to their social commitment, can make valuable proposals from their respective disciplines. Among these proposals, public space remains valid as classic urban resource of integration between different groups. Moreover, the new intergenerational architecture promotes programmatic fusion and social interaction. As consolidated case study, the Plaza de America's experience in Alicante, Spain, represents an example of combination between social architecture and public space with urban sense. In conclusion, homogeneous habitational proposals and segregated urban models can cause social isolation. Social policies must go to combined initiatives between architecture and public space such as the exposed here, example of social cohesion and city development.

Keywords: public space; social programmes; intergenerational habitat; townscape; social interaction. 


\section{Introducción}

Fruto de los avances y del progreso, el mundo envejece con mucha rapidez ${ }^{1}$. La esperanza de vida de la población mundial económica, social, tecnológica y culturalmente más avanzada, crece a un ritmo muy ágil. Esta circunstancia está llevando a que antropólogos, sociólogos, politólogos y otros científicos sociales traten de indagar nuevas iniciativas teóricas para estrechar la brecha generacional entre los diferentes segmentos etarios de la población urbana. A los arquitectos y urbanistas les corresponde la labor de dar respuesta a esas necesidades teóricas mediante propuestas prácticas que formalicen dichas hipótesis sociales y promuevan nuevos lazos de unión intergeneracional. La Segunda Asamblea Mundial sobre Envejecimiento recomienda la solidaridad entre las generaciones a todos los niveles -las familias, las comunidades y las naciones- como algo fundamental para el logro de una sociedad equitativa en todas las edades. La solidaridad constituye también un requisito previo primordial de la cohesión social y es el fundamento tanto de los programas benéficos públicos estructurados como de los sistemas asistenciales no estructurados ( $\mathrm{Na}$ ciones Unidas, 2002).

El espacio público como concepto urbano va mas allá de una simple variable de la ciudad, ya que es la ciudad en si misma (Borja, 2003; García-Doménech, 2016). De hecho, el espacio público es la herramienta no sólo más eficaz, sino también más eficiente para promover el encuentro humano y el intercambio social, bases teóricas de toda urbanidad (Milagres, 2011). El espacio público -le incluso ocasionalmente el colectivo, interpretado como el espacio comunitario dentro de ámbitos privados (Bamba Vicente, 2016)- debe ser el lugar más relevante de la ciudad, pues representa mejor que cualquier otro artificio el reflejo de una sociedad urbana avanzada y equitativa (Moisset,

1. La natalidad y mortalidad de la población mundial han tenido un considerable descenso particularmente durante la segunda mitad del siglo pasado. La natalidad disminuyó entre los años 1950 y 2000 de 37,6 a 22,7 nacimientos por cada mil habitantes; mientras que la mortalidad pasó de 19,6 defunciones por cada mil habitantes a 9,2, en el mismo periodo (Naciones Unidas, 2017).
2014). De otra manera podríamos decir que el espacio público es el que hace la ciudad y la define, diferenciándola de una simple agrupación de casas y edificios.

Una de las mayores preocupaciones de la Modernidad en arquitectura y urbanismo fue la de resolver las necesidades habitacionales, especialmente las de carácter social. Pero por contra, para los pioneros del Movimiento Moderno, el espacio público urbano había sido marginado de sus postulados: "si enfocamos el concepto desde el urbanismo racionalista heredero de la Carta de Atenas, el espacio público es el gran olvidado, un residuo espacial tras la implantación de una arquitectura funcional triunfante" (García-Doménech, 2015a: 204).

A pesar de las numerosas aportaciones y estudios críticos que, apoyados por el importante auge de las ciencias sociales en el mundo urbano, surgieron a partir de la segunda mitad del siglo $X X$, algunas tendencias de sus últimas décadas, acabaron desfigurando lo público hacia la privatización (Azócar Weisser, 2006) y hacia un difuso espectro de lo que se considera, en sentido amplio, como pensamiento urbano posmoderno (Amendola, 2000; Salcedo-Hansen, 2002). Pero lo cierto, es que "no sólo no hay contradicción entre el uso del espacio público y el fortalecimiento de características personales, de índole individual o privada, sino que se fortalecen mutuamente. El espacio público contribuye a enriquecer tanto el espacio privado como el social" (Segovia y Neira, 2005:181). Los espacios públicos siguen siendo lugares de socialización, integración y relación, lugares en los que se produce una experiencia de identidad colectiva que no sabe de diferencias sociales, raciales, económicas o generacionales. Es un lugar de todos y para todos. Con independencia de los aspectos funcionales, el espacio público necesita ser identificado como lugar de igualdad e integración social por la ciudadanía. Esa meta sólo puede conseguirse mediante un conjunto complejo de factores determinantes que incluyen variables culturales, políticas y sociales, pero la arquitectura puede -y debe- 


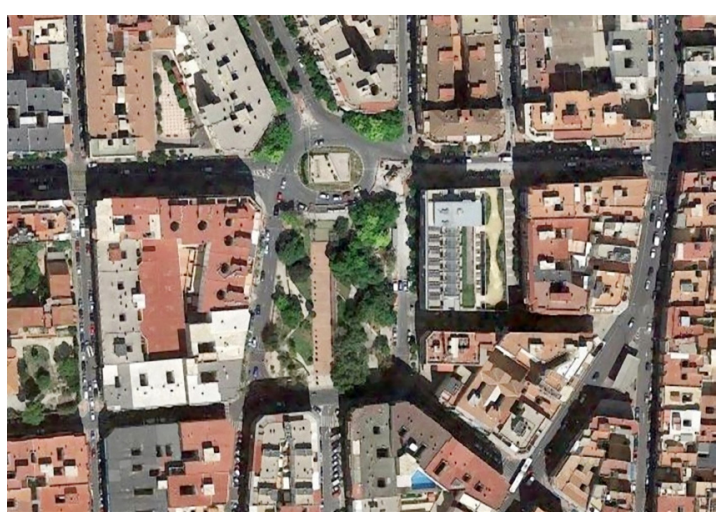

ser la disciplina que diseñe y formalice ese objetivo al servicio del habitante urbano.

Alicante es una ciudad media española de fuertes raíces mediterráneas que ha promovido una actuación social puntera en el hábitat intergeneracional y su relación con el espacio público. Seis años de funcionamiento del programa público intergeneracional y resultados reconocidos a nivel internacional han posicionado este tipo de iniciativas sociales en el foco de interés de varios países europeos y americanos (Luna Torres, 2009; García-Doménech y Martí, 2014; Agudo Martínez, 2015; Delgado-Acosta, Calero-Martí y González-Bencomo, 2016; Kaplan, Sánchez y Hoffman, 2017; Moral Jiménez, 2017). En este caso, la puesta en práctica de un hábitat intergeneracional frente a un espacio público de diseño y funcionamiento previamente reconocido (García-Doménech, 2016) ha integrado un conjunto urbano de elevado interés social para la ciudad y ha creado un paradigma de sentido público, integración colectiva y política residencial inclusiva, tanto a nivel de problema social como de localización y calidad del hábitat (Del Río, 2015). ${ }^{2}$

\footnotetext{
2. Del Río, en su estudio particular, hace referencia a la importancia de la localización residencial en el marco de la ciudad desde una óptica de política pública de suelo. Concluye en que uno de los objetivos prioritarios de la política habitacional debería ser la regulación del mercado inmobiliario. Esto es algo que, precisamente, ha sido llevado a la práctica dentro del programa habitacional intergeneracional de nuestro caso de estudio, en el que la administración pública ha efectuado operaciones de obtención de suelo con fines residenciales sociales, en localizaciones atractivas para el mercado de suelo, frenando la especulación.
}

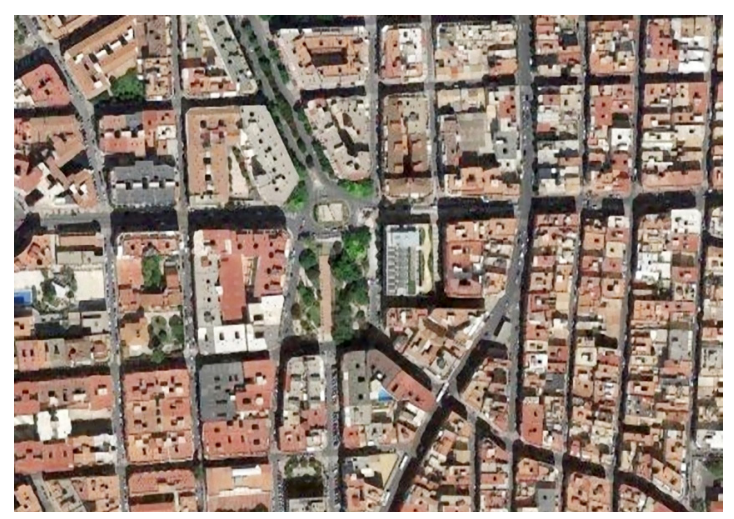

\section{El hábitat intergeneracional}

El modelo de hábitat intergeneracional intenta promover la mediación entre diferentes grupos etarios, facilitando tanto el contacto socio-comunitario en general, como las interrelaciones entre jóvenes y mayores en particular, con un fin integrador y sobre todo de amalgama social (Kaplan, 1997). Adicionalmente, la cohabitación entre diferentes grupos generacionales resuelve la necesidad -y el derecho- a disponer de vivienda digna a dos franjas etarias especialmente vulnerables a la hora de acceder al mercado inmobiliario, como son los jóvenes y los mayores. La arquitectura residencial intergeneracional se ha de orientar especialmente hacia la innovación funcional de los espacios comunitarios e integrarse con otros usos compatibles al residencial, por lo general de carácter netamente público. Con todo ello, el objetivo es potenciar las directrices de integración social, adaptación arquitectónica y habitabilidad. De ahí que en el hábitat intergeneracional, los programas de gestión social deban mantener el mismo nivel de importancia que los programas puramente funcionales necesarios en toda arquitectura. Así, aparecen nuevas variables antropológicas de diseño y adaptación, como la estabilidad, el sentido de identidad y la interdependencia. Los programas gestores de habitabilidad intergeneracional se fundamentan en la propiedad pública del inmueble, en el alquiler social y en el control -también público- tanto del mercado de arrendamiento como del compromiso interactivo y colaborador entre inquilinos de diferentes franjas etarias (Castro Gallardo, 2012). La proporción habitual 
Figura 3: Perspectiva ángulo sureste del edificio intergeneracional. El volumen de las dos primeras plantas se destina para los servicios públicos. Fuente: Patronato Municipal de la Vivienda de Alicante

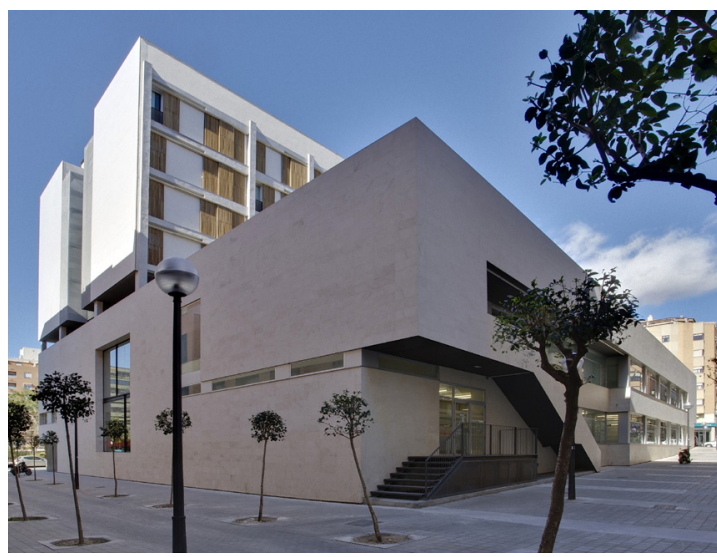

Figura 5: Vista interior de los espacios colectivos del edificio intergeneracional. Fuente: Patronato Municipal de la Vivienda de Alicante

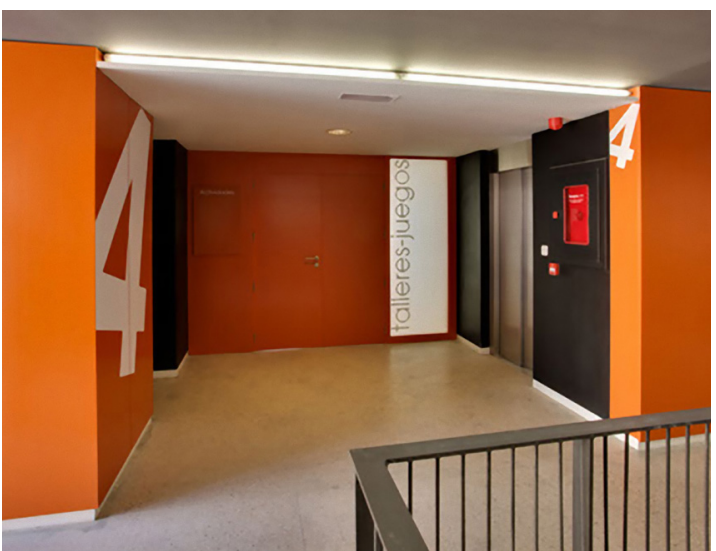

es de una unidad residencial para jóvenes por cada cuatro para mayores. ${ }^{3}$ Éstos han de poder valerse por sí mismos o al menos no presentar dependencias severas. La arquitectura no tiene por qué excluir otros usos compatibles. Es más, resulta interesante la combinación con servicios públicos afines, especialmente los de carácter asistencial. Esta circunstancia potencia el uso público y abre los servicios del edificio al conjunto de la ciudad. Por este motivo, la

3. Los programas de cohabitación intergeneracional no suelen justificar la proporción entre unidades para mayores/jóvenes con criterios demográficos, funcionales o antropológicos, sino sociales, culturales y económicos, adaptados además en particular, a la realidad de la demanda social de la ciudad en la que se implantan. Así, la citada proporción es la empleada más habitualmente por los programas intergeneracionales
Figura 4: Perspectiva ángulo noroeste del edificio intergeneracional. Las cuatro plantas de los volúmenes superiores son las destinadas a las viviendas. Fuente: elaboración propia

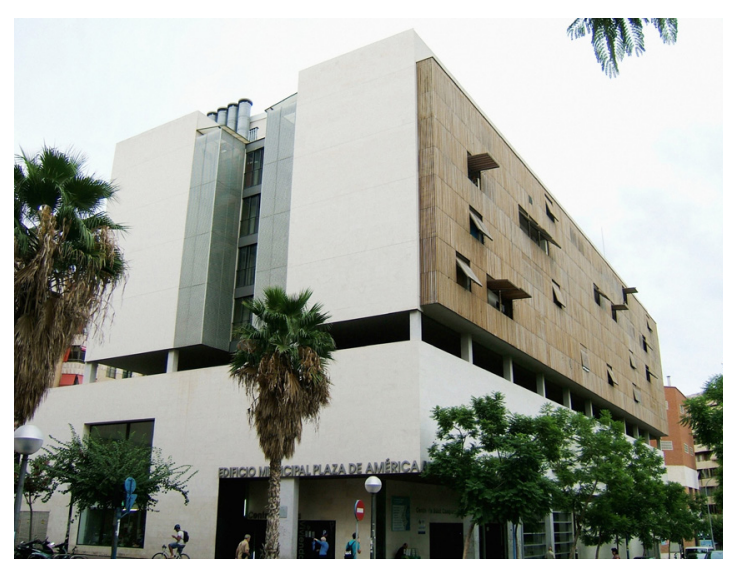

Figura 6: Sección transversal por el módulo de espacios comunitarios. Fuente: Patronato Municipal de la Vivienda de Alicante.

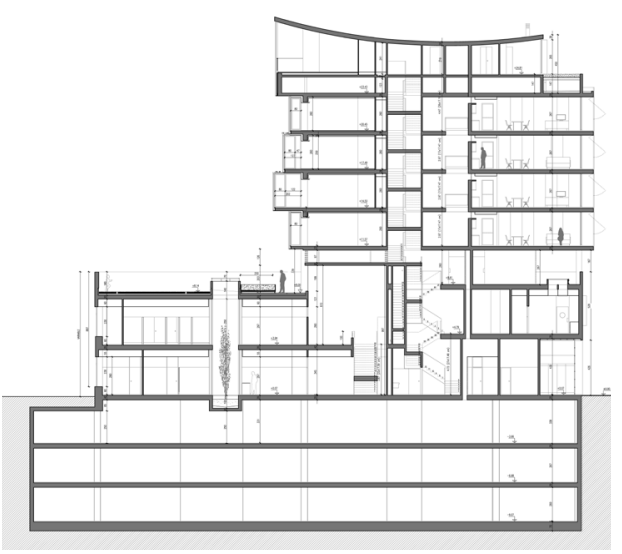

ubicación de este tipo de inmuebles multifuncionales en el conjunto de la ciudad, su accesibilidad y centralidad urbana, y la calidad de su arquitectura suponen variables fundamentales del modelo intergeneracional (García-Doménech y Martí, 2014).

La plaza de América y el edificio residencial intergeneracional homónimo, están situados en Alicante, ciudad media española integrada en la región de la Comunidad Valenciana. La ciudad se caracteriza por una fuerte cultura latino-mediterránea. Este enclave se enmarca en Pla-Carolinas, un populoso barrio de la zona norte de la ciudad, en la intersección de dos importantes viales, de forma que la plaza cumple una función articuladora entre 
Figuras 7 y 8: Perspectiva ángulo noreste y detalle del volumen con los espacios comunitarios del edificio intergeneracional. Fuente: elaboración propia

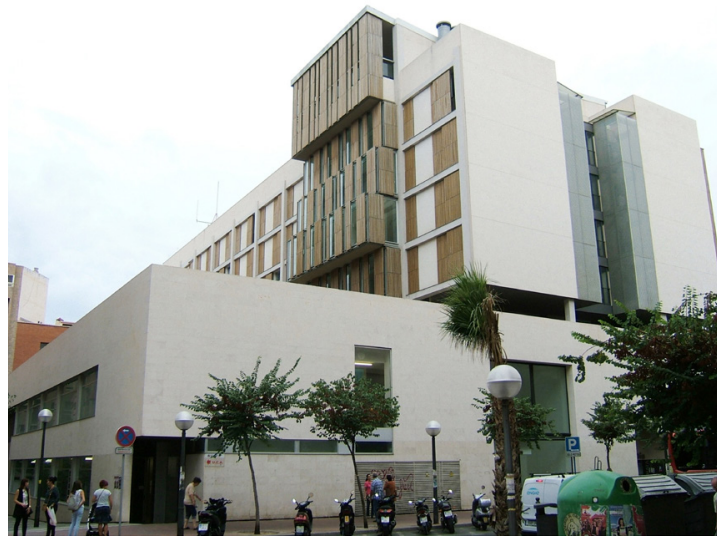

Figura 9: Planta tipo, con viviendas y zona comunitaria. Fuente: Patronato Municipal de la Vivienda de Alicante

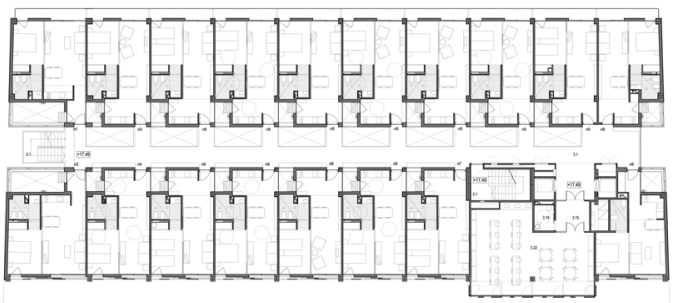

dos tejidos urbanos claramente diferenciados (Figuras 1 y 2). El programa del edificio intergeneracional incluye un total de 72 viviendas, un centro de salud pública, otro de asistencia a mayores, y un aparcamiento subterráneo. El edificio expresa la consideración urbana de la propuesta, combinando funciones privadas y públicas con un lenguaje moderno que clarifica la necesaria funcionalidad del inmueble (Figuras 3 y 4). En el interior, aparece una constante orientación icónica y cromática de las diferentes estancias privadas y colectivas (Figura 5) que facilitan sobremanera su lectura arquitectónica. Las zonas comunitarias se reparten equitativamente entre las diferentes plantas del edificio con el fin de promover la interacción social mediante "espacios de contacto intergeneracional" (Kaplan, Sánchez y Hoffman, 2017:129-130) pero al mismo tiempo,

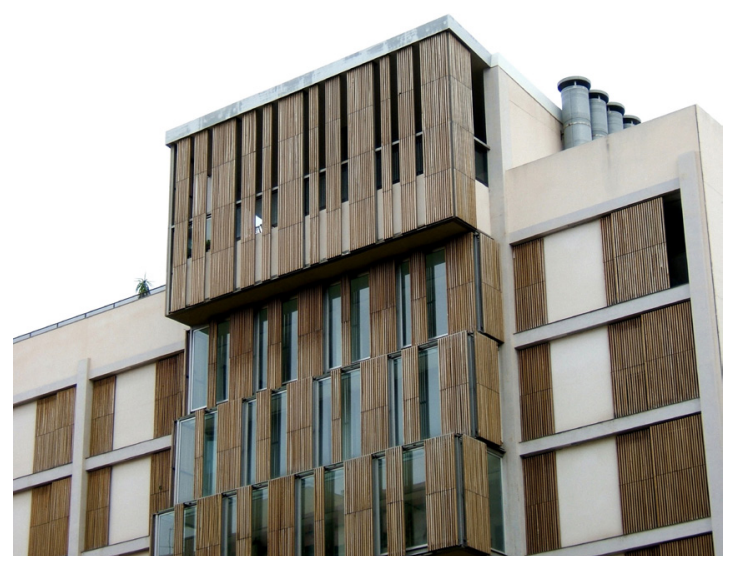

el conjunto volumétrico de estas zonas presenta una clara lectura en fachada indicativa de que se trata de un espacio singular en la composición (Figuras 6, 7 y 8).

Las unidades residenciales son viviendas de $40 \mathrm{~m} 2$ repartidas en cuatro plantas (Figura 9). Su diseño se adapta a las necesidades de accesibilidad de inquilinos mayores no dependientes y al mismo tiempo, no plantean conflicto funcional alguno cuando los inquilinos son personas jóvenes. Mediante correderas, salón y dormitorio pueden crear un único espacio, así como también la cocina y el comedor (Figura 10). Todas son exteriores con orientación este-oeste, así que para moderar las temperaturas de las viviendas orientadas a poniente, se establece una densa celosía practicable de madera (Figura 11). De nuevo el juego de volúmenes del proyecto evidencia los dos módulos residenciales articulados por un patio abierto que recorre longitudinalmente todo el edificio. En este patio se establecen los accesos mediante corredores y al mismo tiempo garantiza la ventilación cruzada. En las dos primeras plantas se alojan los servicios públicos asistenciales con espacios a doble altura (Figuras 12, 13 y 14).

El voluntariado y la ayuda mutua desinteresada suele ser una práctica habitual en los diversos programas residenciales para las personas mayores (Laterza Calosso, 2015), pero en el caso expuesto, la gestión del hábitat intergeneracional es la base sobre la que se 
Figuras 10 y 11: Imagen interior de una de las viviendas hacia el este y detalle fachada oeste desde la plaza. Fuente: Patronato Municipal de la Vivienda de Alicante y elaboración propia

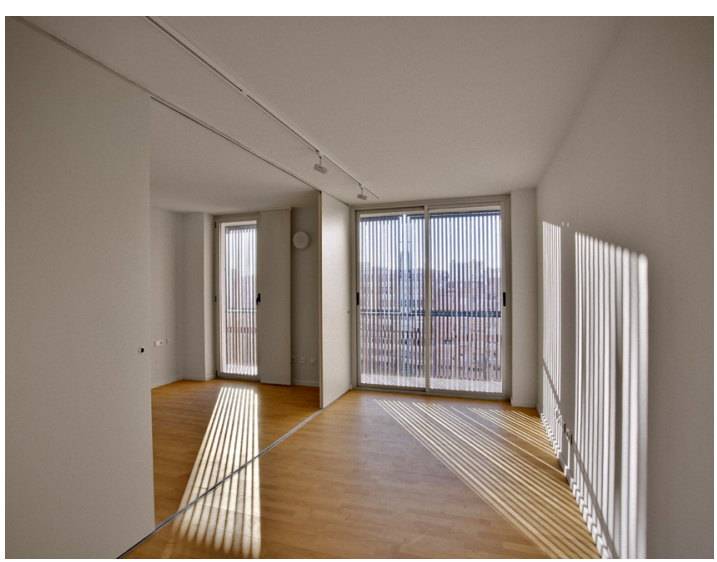

Figura 12: Plano de planta primera destinada a servicios públicos asistenciales. Fuente: Patronato Municipal de la Vivienda de Alicante

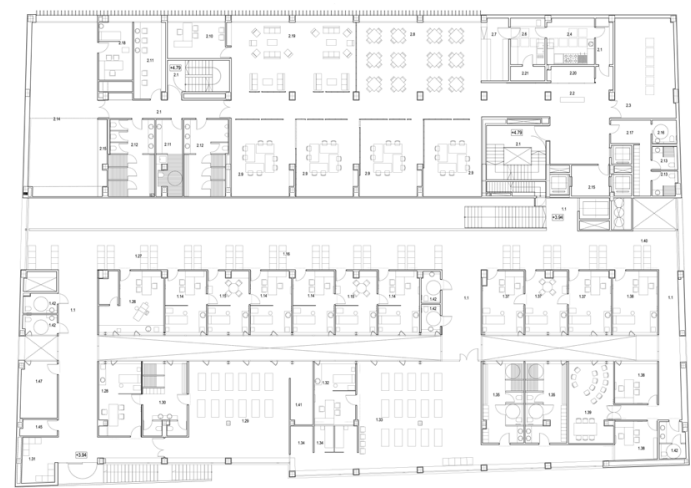

asienta su auténtica dimensión social. El propio ayuntamiento, como organismo público propietario del edificio, arbitra tanto los criterios de prioridad de acceso al arrendamiento de las viviendas como el eficaz cumplimiento de los compromisos de interacción intergeneracional entre los inquilinos. Por otra parte, la experiencia de la convivencia intergeneracional no limita la privacidad de la vida personal: la actitud requerida es fundamentalmente participativa con el fin de promover la interacción entre generaciones mediante actividades comunitarias. Para poder arrendar una vivienda intergeneracional han de darse unas circunstancias personales y económicas que faciliten el acceso a quienes más lo necesitan. Los mayores han de superar los 65 años, carecer de vivienda en propiedad, estar empadronado en la ciudad durante al menos cinco años, no presentar

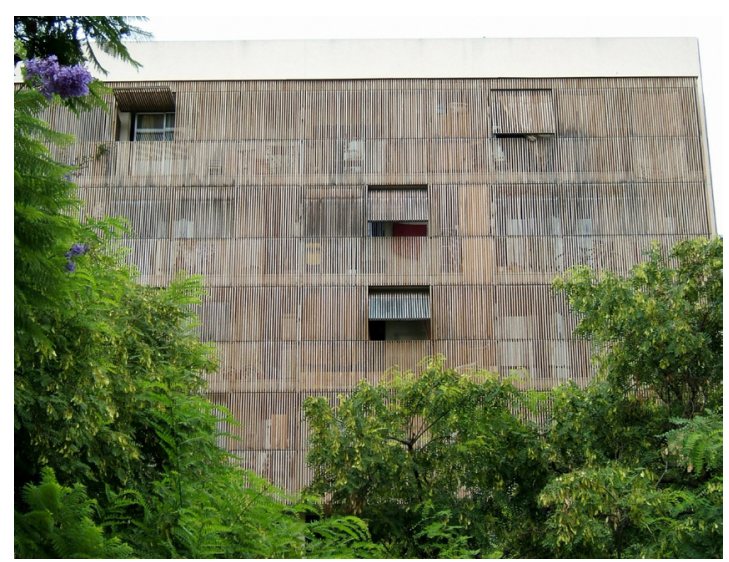

estados de dependencia física severa y disponer de unos ingresos limitados. ${ }^{4}$ El $20 \%$ de viviendas son reservadas a jóvenes que no superen los 35 años y que mantengan similares requisitos a los mayores, incluso el techo de ingresos personales, pero en este caso deben acreditar también un mínimo que garantice el pago del alquiler social. ${ }^{5}$ Tanto mayores como jóvenes pueden acceder al alquiler de una vivienda intergeneracional solos o en pareja.

Los compromisos de interacción intergeneracional se establecen contractualmente en el propio acto del arrendamiento: los jóvenes quedan obligados a dedicar cuatro horas a la semana de apoyo social a la comunidad de inquilinos mayores. Esta labor de apoyo social no se interpreta como una responsabilidad profesional -competencia de los trabajadores sociales- sino como un apoyo a la colectividad y a la filosofía del programa. La verdadera interacción no se produce en la privacidad de las viviendas, sino en los espacios comunitarios del edificio, incluyendo tanto zonas colectivas generales como cubiertas y patios (Bamba Vicente, 2016), como estancias expresamente ubicadas y diseñadas para facilitar este trabajo social de integración intergeneracional: "las personas mayores se sienten más seguras a la vez que perciben la presencia de redes de apoyo mutuas, por ejemplo entre vecinos al

4. Inferiores a $21.000 €$ anuales (aprox. 436.596 pesos ARS)

5. 5.000 $€$ anuales (aprox. 103.952 pesos ARS). 
Figuras 13 y 14: Planta baja y primera en las que se sitúan los servicios asistenciales públicos y detalle de hueco de iluminación común a doble altura en la fachada norte. Fuente: Patronato Municipal de la Vivienda de Alicante

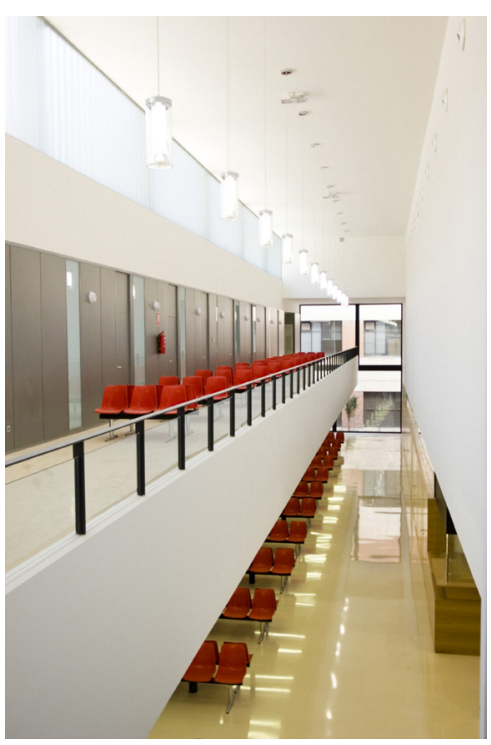

momento de precisar una ayuda o simplemente para socializar" (Passantino, Roumec, Fernández \& Laterza Calosso, 2015:24).

Entre las labores interactivas se realizan pequeñas celebraciones personales, como aniversarios o cumpleaños; actividades culturales comunitarias, incluyendo la gestión de una pequeña biblioteca y videoteca; ayuda de los jóvenes hacia los mayores con la iniciación o mejora en el manejo de las nuevas tecnologías como la informática, internet o el manejo de celulares; el cuidado conjunto de los espacios ajardinados y de la pequeña huerta urbana de la cubierta comunitaria, y en definitiva, simples apoyos para algunas labores cotidianas. Estos apoyos no son sustitutivos de los familiares o de los profesionales, sino los característicos de la tradición vecinal de la cultura mediterránea. Pero tan importante es el funcionamiento interno del edificio como la integración del mismo en su entorno urbano y en particular, su diálogo funcional con el espacio público inmediato de la preexistente plaza de América.

\section{El espacio público y su función social}

La ciudad es un artificio conformado por un conjunto de espacios privados y públicos en el que las personas pueden vivir y desarrollarse

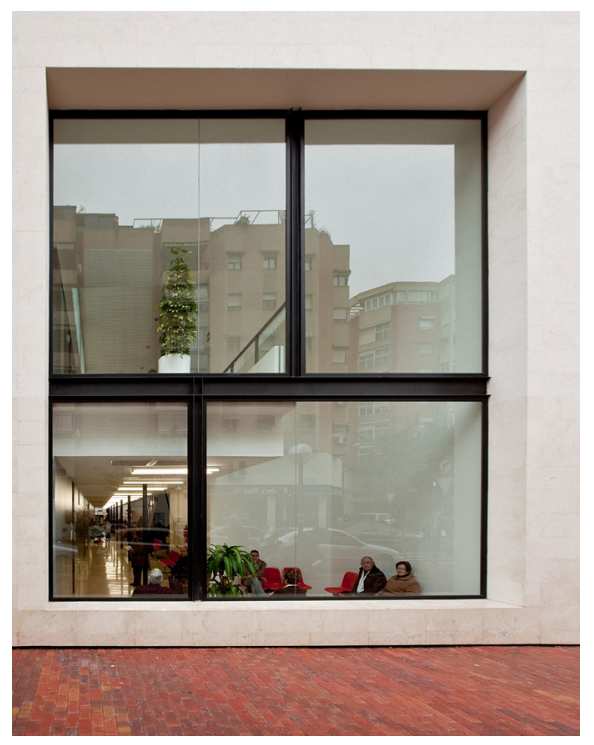

como individuos -habitantes-, pero en el que también convivir y desarrollarse como colectivo -cohabitantes-, de forma que en justo equilibrio puedan a conformar el estatus ciudadano. Y en la ciudad, el espacio público es su quintaesencia constitutiva, un lugar en el que es posible combinar lo temporal, lo espacial y lo social (García-Doménech, 2015a). El espacio público es fiel reflejo de la identidad urbana, el lugar en el que la interacción colectiva pone en evidencia la necesidad de su existencia, pues el espacio público es el lugar en el que se celebra la mayor parte de la vida y de la actividad urbana. En ese sentido, la apertura a la sociedad en su conjunto y la capacidad potencial del encuentro personal son variables que caracterizan directamente al espacio público (Arribas y Manzi, 2005). Podemos interpretar la identidad como la cualidad tanto de reconocerse como de ser reconocido. Por lo tanto, la identidad urbana es la cualidad que tiene la ciudad -o un barrio de la misma- para que sus habitantes la reconozcan y al mismo tiempo, sea reconocible para los demás: "si se organiza el medio ambiente y se identifica claramente, el ciudadano puede otorgarle sus propios significados y conexiones. Entonces se convertirá en un auténtico lugar, notable e inconfundible"6 (Lynch, 1960:92). El espacio público regula la

6. Traducción propia de la cita original: "if the environment is 
Figuras 15: Planta general de ordenación de la plaza de América. Fuente: Ayuntamiento de Alicante

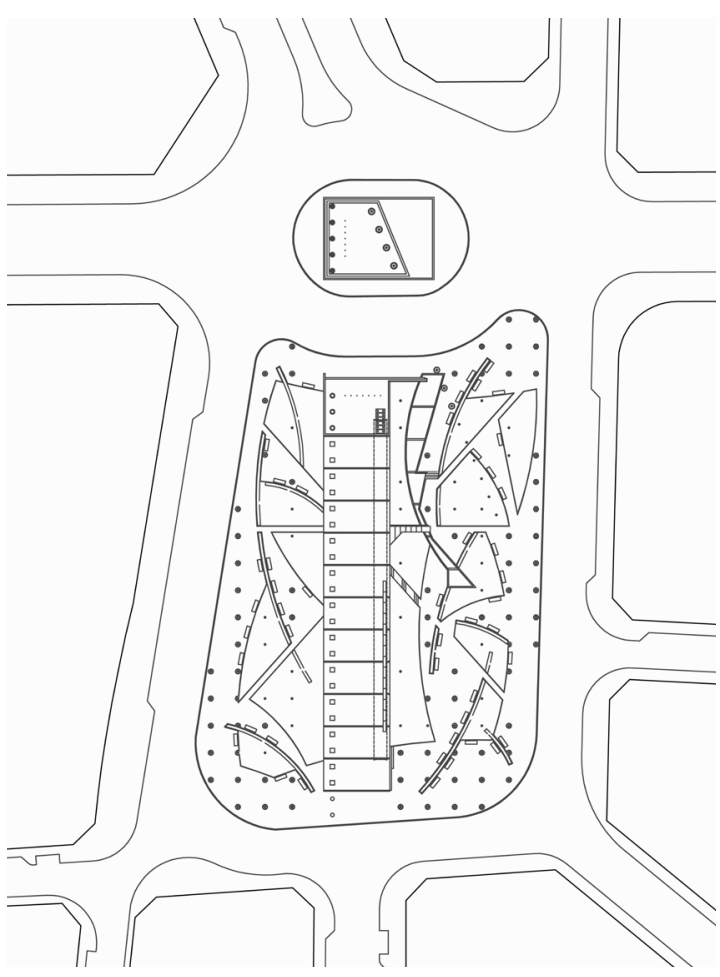

cohesión social, canaliza las manifestaciones ciudadanas y promueve las relaciones interpersonales, incluyendo las intergeneracionales (Delgado-Acosta, Calero-Martí y González-Bencomo, 2016). La vinculación entre la sociedad urbana y el espacio que habita confluye hacia la idea de "apropiación" del espacio y "pertenencia" al mismo a modo de "fuente de seguridad y satisfacción derivadas del apego al lugar" (Vidal y Pol, 2005:286). De hecho, variables claramente emocionales y afectivas como la alegría, el cariño o el orgullo, suelen ser frecuentemente esgrimidas por los usuarios de los espacios públicos y los habitantes de su entorno residencial (Segovia y Neira, 2005). En el caso de estudio, el espacio público creado en la plaza de América frente al solar en el que estaba prevista la posterior puesta en práctica de un hábitat intergeneracional, planteaba de antemano la existencia de una cierta identidad urbana que iba a potenciar el posterior proyecto social, extendiendo sus bondades a todo el entorno urbano.

visibly organized and sharply identified, then the citizen can inform it with his own meanings and connections. Then it will become a true place, remarkable and unmistakable".
Figuras 16 y 17: Perspectivas generales de la plaza de América. Fuente: elaboración propia
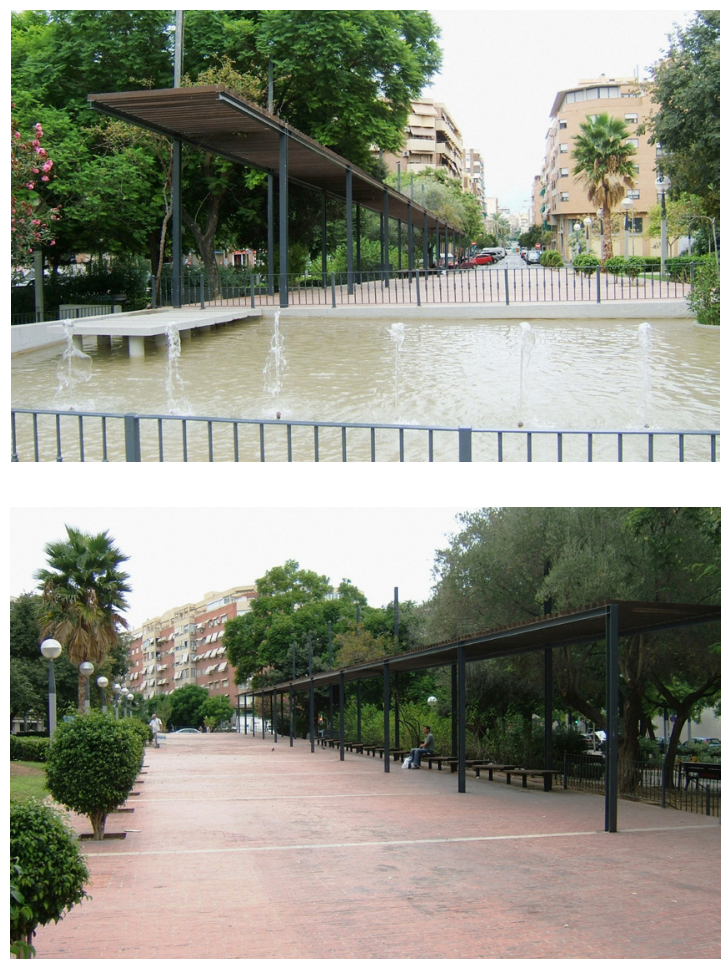

Algunas plazas urbanas han contribuido a potenciar el sentido de identidad del propio espacio público, pero también de la arquitectura de su entorno. En ese sentido, la plaza de América se postula como lugar de encuentro para su entorno urbano. Tras su urbanización, este espacio urbano dejó de ser un simple aparcamiento residual para convertirse en lugar de encuentro ciudadano. La plaza crea un espacio abierto y dialogante, pero a la vez unitario e independiente del entorno: constituye un ejemplo de invención de un lugar allí donde inexistía, tanto desde un enfoque estático y de encuentro (Augé, 1993) como dinámico y con múltiples significados para los transeúntes (Jirón e Iturra, 2011). La actitud social de la plaza ya parte de la propia gestión de su proyecto, puesto que el diseño fue activamente participado por el vecindario (García-Doménech, 2016), acentuando el concepto de "identidad social urbana" (Valera y Pol, 1994:10-16).

La plaza de América se articula mediante un eje central (Figura 15) en el sentido longitudinal del espacio, pavimentado con adoquín cerámico y potenciado visualmente mediante 


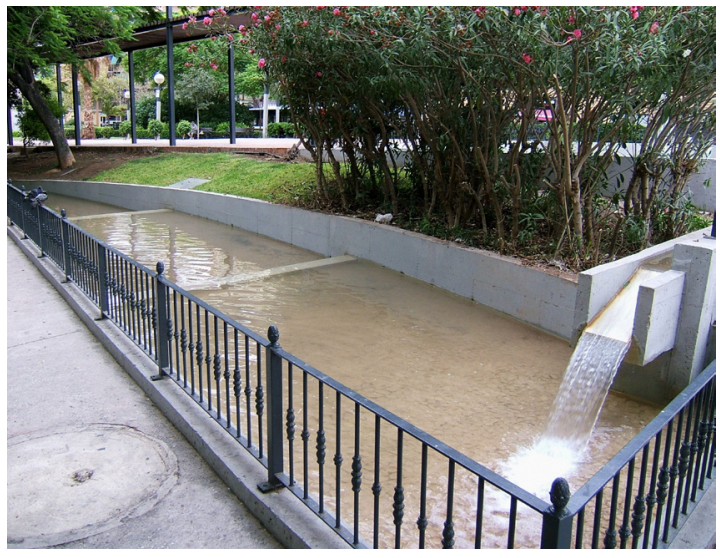

Figura 20: Perspectiva general del edificio intergeneracional desde la plaza de América Fuente: elaboración propia

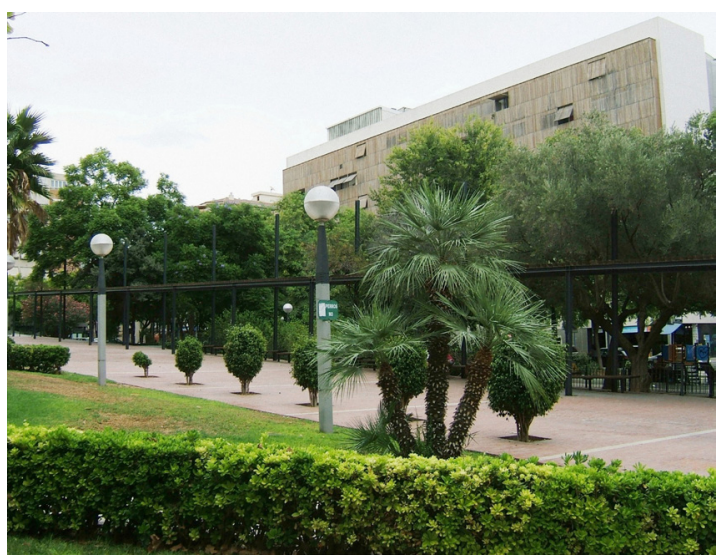

una pérgola continua, construida en seco con acero y madera. Bajo esta pérgola, se integra una bancada de madera escalonada para salvar la pendiente natural del terreno (Figuras 16 y 17). Precisamente esa pendiente sirvió de base para poner en práctica una "acción reflexiva recíproca” (González, García y Salazar, 2011:31) junto a otros técnicos y usuarios para proponer uno de los recursos paisajísticos más significativos del diseño de la plaza: una fuente que, partiendo de la isleta viaria cuya función sólo es la de referencia y regulación del tráfico rodado, adquiere su verdadero protagonismo cuando vuelve a emanar de una alberca situada en el extremo norte de la zona de estancia de la plaza. Esta alberca está en la cota más elevada de esa zona de estancia, lo que permite crear una propuesta lúdica de cascadas que, aprovechando la pendiente natural del

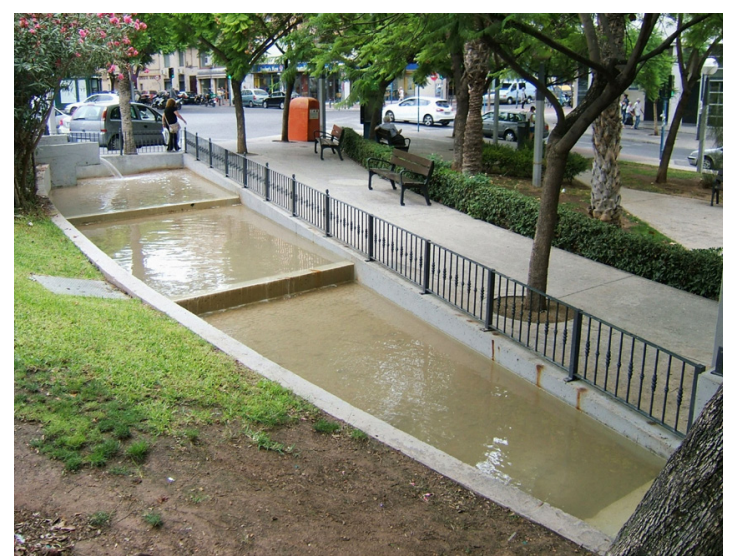

terreno, discurre en la parte este de la plaza, precisamente la adyacente al edificio intergeneracional (Figuras 18, 19 y 20). Este juego hidráulico explota otras variables sensoriales complementarias de las visuales, mejorando las condiciones ambientales y creando una percepción sonora agradable frente al ruido del tráfico circundante: "Ios espacios públicos tienen sus sonidos característicos, que no tienen por qué ser perturbadores y pueden resultar agradables. Es más, pueden contribuir a fortalecer la sensación de lugar que acompaña a un espacio público de calidad" (García-Doménech, 2015b:62). La calidad formal del espacio público como lugar agradable facilita e incide sobre las relaciones interpersonales: "cuando el diseño del espacio público logra establecer una comunicación armónica con quienes lo habitan, favorece acciones de apropiación sobre él como manifestación del vínculo que desarrollan las personas con el territorio, a la vez que [...] otorga el ambiente adecuado para el establecimiento de dinámicas sociales colectivas." (Caquimbo Salazar, 2008:83).

\section{Conclusiones}

El conjunto formado por los espacios habitables y la ciudad, o lo que es lo mismo, por la arquitectura y el espacio público, es el binomio en el que reside el éxito de un proyecto social. La observación y análisis del caso expuesto evidencia y ejemplifica esta hipótesis. Tanto el proyecto residencial como el proyecto urbano del espacio público, aun manteniendo 
diferencias en tiempos y autoría, se complementan consiguiendo crear un enclave urbano solidario al servicio de la sociedad. La puesta en práctica de esta regla ha resultado ser especialmente útil para el desarrollo de las relaciones intergeneracionales, lo que a su vez ha supuesto un importante impulso para la cohesión social. El estudio de caso expuesto confirma la necesidad de buscar soluciones sociales al envejecimiento de la población en los países industrializados. La política social, los programas intergeneracionales, la nueva arquitectura especializada y la tradición integradora del espacio público contribuyen por partes iguales a evitar la exclusión generacional. Por ello es deseable que toda iniciativa similar -sea pública, privada o mixta- venga amparada por un plan integral de carácter multidisciplinar que abarque el espectro político, económico y social y que a su vez, este plan se presente avalado por una arquitectura y diseño urbano de calidad.

Todo proyecto intergeneracional -en su sentido amplio, no sólo en el arquitectónico- no puede mantenerse al margen de su relación con la ciudad. Una implantación periférica puede acabar por aislar a determinados colectivos sensibles, dispersar la ciudad, segregar la sociedad y en definitiva debilitar la cohesión social. Al mismo tiempo, el diálogo entre la nueva arquitectura intergeneracional y el tradicional arraigo y buen funcionamiento del espacio público en la cultura latina, puede generar o mejorar un deseable sentido tanto de identidad urbana como de conciencia ciudadana. En el caso estudiado, la plaza, como marco urbano del conjunto, supone una parte sustancial del plan tanto por su diseño como por su aportación funcional. Este espacio público constituye un ejemplo de cómo crear un fragmento urbano con identidad en un entorno inicialmente carente del mismo. La arquitectura intergeneracional implantada frente a la plaza, ha sabido aprovechar esa virtud y trasladarla a su programa arquitectónico. En el fondo la arquitectura, es el reflejo formal de una necesidad social y en este caso, se ha experimentado satisfactoriamente un hábitat totalmente contrapuesto a las tradicionales residencias para mayores aisladas y carentes de relaciones intergeneracionales, más allá de las puramente familiares o profesionales. Estos vínculos entre diferentes generaciones ha potenciado la solidaridad entre jóvenes y mayores, la interacción formativa entre ambos y la cohesión colectiva.

Por otra parte, el proyecto de hábitat intergeneracional de la plaza de América ha puesto en evidencia la necesidad de que las diferentes franjas etarias de la sociedad compartan sus actividades y sus vivencias urbanas, eliminando cualquier juicio previo de carácter social y esto es algo que el espacio público viene enseñándonos desde los albores del fenómeno urbano. Las relaciones intergeneracionales de este programa han servido para impulsar el sentimiento de pertenencia colectivo, la integración social y la condición ciudadana. La residencia compartida entre diferentes generaciones, con espacios comunitarios diseñados expresamente para impulsar este tipo de relaciones, ha eliminado el secular aislamiento que la sociedad contemporánea impone a las personas mayores. Todo ello sin renunciar a la inherente necesidad humana de independencia, desarrollada en la privacidad de la vivienda particular. La sociedad en general y la urbana en particular, ha de apostar por modelos de integración intergeneracional a fin de que los mayores mantengan un envejecimiento activo y a la par proactivo con los jóvenes. La consecución de este objetivo supondrá un importante avance social al que arquitectos y urbanistas han de contribuir.

\section{Bibliografía}

Agudo Martínez, M.J. (2015). Arquitectura intergeneracional. En Gómez Méndez, J.M. et al. (eds.), Derechos humanos emergentes y periodismo (pp. 12-20). Sevilla: Universidad de Sevilla.

Amendola, G. (2000): La ciudad postmoderna. Magia y miedo de la metrópolis contemporánea. Edición traducida por M. García Vergaray y P. Sustersic. Madrid: Celeste. (Edición original publicada en 1997)

Arribas, M.I. \& Manzi, G. (2005). "Espacio público: ¿de quién es este lugar? El caso del Barrio Universitario de Santiago". Revista 180, 15, pp. 50-53. 
Augé, M. (1993). Los No-Lugares. Espacios del anonimato. Una antropología de la sobremodernidad. Edición traducida por M.N. Mizraji. Barcelona: Gedisa. (Edición original publicada en 1992).

Azócar Weisser, J.S. (2006). "Política chilena de vivienda social: una mirada a su concepto de espacio público en la posmodernidad". Revista INVI. 21(57), pp. 10-43.

Bamba Vicente, J.C. (2016). "La vivienda social en Guayaquil (1940-1970): procesos de transformación en los espacios colectivos". Arquitecturas del Sur, 34(49), pp. 66-79.

Borja, J. (2003). La ciudad conquistada. Madrid: Alianza.

Caquimbo Salazar, S. (2008). "La calidad del espacio público en la construcción del paisaje urbano. En busca de un hábitat equitativo". Revista INVI. 22(62), pp. 75-97.

Castro Gallardo, M. (2012). Relaciones intergeneracionales y bienestar de las personas mayores. Granada: Editorial de la Universidad de Granada.

Del Río, J.P. (2015). "La vivienda social y la cuestión urbana. Consideraciones teóricas para el análisis de las políticas de hábitat". Estudios del hábitat, 13(1), pp. 76-92.

Delgado-Acosta, C.R., Calero-Martí, C.G. \& González-Bencomo, H. (2016). "Potencialidad de los espacios públicos abiertos para las relaciones intergeneracionales. Un estudio de caso en la ciudad de Santa Cruz de Tenerife (Canarias, España)". Documents d'Anàlisi Geogràfica, 62(1), pp. 5-25.

García-Doménech, S. \& Martí, P. (2014). Arquitectura intergeneracional y espacio público. ARQ, 86, pp. 62-69.

García-Doménech, S. (2015a). "Estética e interacción social en la identidad del espacio público". Arte y Ciudad, 7, pp. $195-212$.

García-Doménech, S. (2015b). "Urban aesthetics and social function of actual public space: a desirable balance". Theoretical and Empirical Researches in Urban Management, 10(4), pp. 54-65.

García-Doménech, S. (2016). Transformación del espacio público en Alicante (1975-1995). Reflejo urbano de una sociedad en transición. Alicante: Instituto de Cultura Juan Gil-Albert.

González, A., García, A. \& Salazar, J. (2011). "Práctica reflexiva recíproca para el diseño ambiental del espacio público". Arquitecturas del Sur, 39, pp. 28-43.

Jirón, P. \& Iturra, L. (2011). "Momentos móviles. Los lugares móviles y la nueva construcción del espacio público". Arquitecturas del Sur, 39, pp. 44-57.

Kaplan, M. (1997). "The Benefits of Intergenerational Community Service Projects". Journal of Gerontological Social Work, 28(3), pp. 211-228.

Kaplan, M. Sánchez, M. \& Hoffman, J. (2017). Intergenerational Pathways to a Sustainable Society. Cham: Springer.

Laterza Calosso, J. (2015). "Los espacios para la socialización y/o privacidad de personas mayores, en las residencias de larga estancia de Mar del Plata". I+A

Investigación y Acción, 17, pp. 85-110.

Luna Torres, L. (2009). Programa De Alojamiento Intergeneracional. Jóvenes universitarios y adultos mayores. En Romero, X. (ed.). Hacia una sociedad para todas las edades. Experiencias latinoamericanas de relaciones intergeneracionales (pp. 81-96). Santiago: Red Latinoamericana de Gerontología.

Lynch, K. (1960). The Image of the City. Cambridge, Massachusetts: MIT Press.

Milagres, L. (2011). "El espacio público cotidiano y la posibilidad de la producción colectiva". Arquitecturas del Sur, 40, pp. 44-55

Moisset, I. (2014). "Arquitectura y ambiente: una perspectiva latinoamericana". Estudios del hábitat, 12(2), pp. 83-95.

Moral Jiménez, M.V. (2017). "Programas intergeneracionales y participación social: la integración de los adultos mayores españoles y latinoamericanos en la comunidad". Universitas Psychologica, 16(1), pp. 1-19.

Naciones Unidas (2002). Informe de la Segunda Asamblea Mundial sobre el Envejecimiento. Madrid.

Naciones Unidas (2017). World Population Prospects. New York.

Passantino, L.D., Roumec, B., Fernández, J. \& Laterza Calosso, J. (2015). "El envejecimiento poblacional y el entorno urbano en la ciudad de Mar del Plata. Ciudad y Vivienda, las particularidades de su área céntrica". Estudios del hábitat, 13(2), pp. 15-25.

Salcedo-Hansen, R. (2002). "El espacio público en el debate actual: una reflexión crítica sobre el urbanismo post-moderno". Eure, 28(84), pp. 5-19.

Segovia, O. \& Neira, H. (2005). "Espacios públicos urbanos: una contribución a la identidad y confianza social y privada". Revista INVI, 20(55), pp. 166-182.

Valera, S. \& Pol, E. (1994). "El concepto de identidad social urbana: una aproximación entre la psicología social y la psicología ambiental". Anuario de Psicología, 62, pp. 5-24.

Vidal, T. \& Pol, E. (2005). "La apropiación del espacio: una propuesta teórica para comprender la vinculación entre las personas y los lugares". Anuario de Psicología, 36(3), pp. 281-297. 